\title{
Urban Density Estimation From Polarimetric SAR Images Based on a POA Correction Method
}

$\operatorname{AUTHOR}(\mathrm{S})$ :

Kajimoto, Muneyoshi; Susaki, Junichi

\section{CITATION:}

Kajimoto, Muneyoshi ... [et al]. Urban Density Estimation From Polarimetric SAR Images Based on a POA Correction Method. IEEE Journal of Selected Topics in Applied Earth Observations and Remote Sensing 2013, 6(3): 1418-1429

ISSUE DATE:

2013-06

URL:

http://hdl.handle.net/2433/193531

\section{RIGHT:}

(c) 2013 IEEE. Personal use of this material is permitted. Permission from IEEE must be obtained for all other uses, in any current or future media, including reprinting/republishing this material for advertising or promotional purposes,

creating new collective works, for resale or redistribution to servers or lists, or reuse of any copyrighted component of this work in other works.; This is not the published version. Please cite only the published version.; この論文は出版社版

でありません。引用の際には出版社版をご確認ご利用ください。 


\title{
Urban Density Estimation from Polarimetric SAR Images Based on a POA Correction Method
}

\author{
Muneyoshi Kajimoto, Student Member, IEEE and Junichi Susaki, Member, IEEE
}

\begin{abstract}
In this paper, an algorithm for estimating urban density from polarimetric synthetic aperture radar (SAR) images is proposed. Polarization orientation angle (POA) and four power components derived by four-component decomposition are used in the algorithm. In particular, in urban areas, SAR data are generally affected by factors such as the interval between buildings, building height, and building azimuth angle. Here, building azimuth (orientation) angle means the relative azimuth between the wall normal and the radar's ground range direction. The interval between buildings and building height are used for building density calculation such as the building-to-land ratio and the floor area ratio. However, building azimuth angle which depends on satellite orbit has almost no relation with building density. The scattering intensity of microwaves emitted from SAR has a strong dependence on this building azimuth angle. Therefore, the main part of this paper is focused on the correction of this angular effect. The first step in the POA correction method is the extraction of homogeneous-POA city districts. In the second step each power component's scattering intensity is normalized for all pixels in a particular POA interval separately for different POA types of districts. In the case of Tokyo metropolitan area, Japan, estimated urban density from ALOS/PALSAR data has correlation coefficients of nearly 0.7 with the building-to-land ratio and 0.5 with the floor area ratio on the scale of hundreds of meter. In the areas where strong POA dependence is seen, the improvement of the correlation coefficient runs up to approximately 0.2 .
\end{abstract}

Index Terms-Four-component decomposition, polarimetric synthetic aperture radar, polarization orientation angle, urban density estimation.

\section{INTRODUCTION}

$\mathrm{U}$ RBAN spaces are rapidly becoming extremely dense, especially in Asian countries. This rapid growth causes various problems, such as poor infrastructure and the urban heat island phenomenon. In understanding the details of an urban space, urban density can be one of the most important indices. Generally, urban density is estimated on the basis of GIS data. However, urban areas are rapidly spreading, especially in developing countries, so it is necessary to regularly update GIS data. Therefore, estimation using satellite

Manuscript received December 26, 2012; revised March 18, 2013; accepted March 20, 2013. This work was supported by a program of the Third Advanced Land Observing Satellite Research Announcement, Japanese Aerospace Exploration Agency, and The Okawa Foundation for Information and Telecommunications.

The authors are with the Department of Civil and Earth Resources Engineering, Graduate School of Engineering, Kyoto University, Kyoto 615-8540, Japan (e-mail: k.muneyoshi0805@gmail.com; susaki.junichi.3r@kyoto-u.ac.jp). data could be a useful method for regularly monitoring urban density, but it has not been practical because of the complex mechanism of backscattering in urban areas.

SAR provides information based on microwaves which are closely related to the target structure, and urban land cover mapping using multitemporal polarimetric synthetic aperture radar (PolSAR) data has been proposed [1]. That study produced a land cover mapping of urban areas where human-made structures are mixed with natural objects. Residential areas were categorized into only two classes (high density or low density) while no density information was given for industrial, commercial, and construction areas. Moreover, there was no detailed urban density estimation.

As studies on urban building density, most of them require GIS data, or the accuracy of density estimation depends on results of urban area extraction [2], [3], [4]. The study [2] utilizes single-band and mono-polarized SAR imagery backscatter values, and then establishes the relationship between the features obtained from SAR imagery and the building density taken from GIS data by using random forests regression algorithm. Instead of using back scatter values, urban area extraction results are made use of and the estimated density is amended with GIS data [3]. In the study [4], only urban area extraction results are used, however density accuracy has a strong dependence on the results of urban area extraction. This means more accurate land cover classification method is required. On the whole, these proposed methods are very sensitive to SAR image preprocessing such as urban area extraction, and require GIS data to establish a regression model. Moreover, estimated urban density with these methods basically has information on only building-to-land ratio which shows how many buildings are standing within a district and no information on building height.

In the present paper, an algorithm is proposed that estimates urban density from only one PolSAR image of an area of interest. After urban area extraction from a PolSAR image using the method proposed in [5], we focus on urban density estimation. The method of urban density estimation proposed in this study utilizes PolSAR imagery backscattering values, which are not greatly affected by the accuracy of urban area extraction and are assumed to include the effect of building height. However, the scattering intensity of microwaves emitted from SAR has a strong dependence on target structure. A large change in scattering intensity is found, dependent on whether the normal to a building's wall is parallel to the 


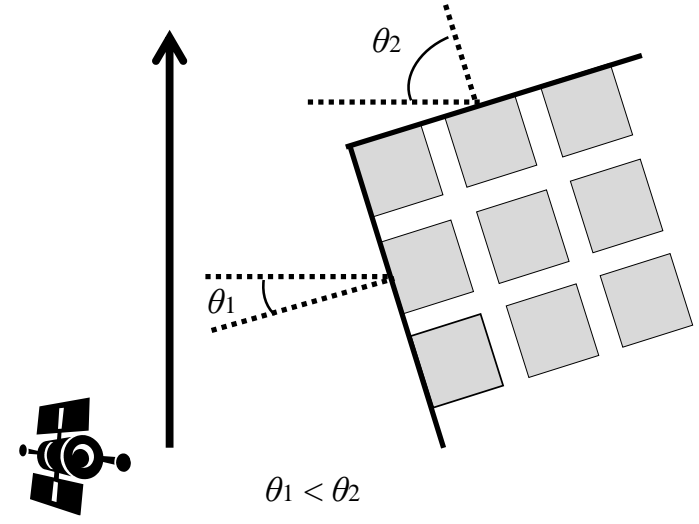

Fig. 1. Relation between target structure and building azimuth.

sensor's ground range direction. If so, the scattering intensity from the buildings is high; otherwise, it is low. Here, building azimuth angle means the relative azimuth between the wall normal and the radar's ground range direction. Building shapes are supposed to be a cuboid, and for each building there are at most two side walls which a sensor can detect. Thus, at most two relative azimuths between the side walls and sensor's ground range direction can be considered. In Fig. 1, relative azimuth with the smaller absolute value of itself $\left(\theta_{1}\right)$ shows a strong back scattering, and the contribution from the other relative azimuth with the larger absolute value of itself $\left(\theta_{2}\right)$ can be considered to be small. Therefore, building azimuth angle in this study is defined as the relative azimuth with the smaller absolute value of the two for each building, $\theta_{1}$ in Fig. 1. This angular effect can be an obstacle to the urban density estimation process. If this effect of building azimuth angle is removed, only the effects of interval between buildings and building height remain, which enables us to estimate urban density. Therefore, we focus on POA correction in this paper.

The remainder of this paper is organized as follows. Section II explains the indices used in the proposed algorithm. X-band experimental data are analyzed in Section III, the algorithm itself is then described in Section IV, and experimental results are reported and discussed in Section V. Finally, we present our conclusions in Section VI.

\section{INDICES USED}

The format of PolSAR data consists of a complex scattering matrix

$$
s=\left(\begin{array}{ll}
S_{H H} & S_{H V} \\
S_{V H} & S_{V V}
\end{array}\right)=\left(\begin{array}{ll}
a & c \\
c & b
\end{array}\right) .
$$

Here, for simplicity, $S_{H V}$ and $S_{V H}$ are assumed to be equivalent, and the coherency matrix is given by

$$
\begin{gathered}
T=\left(\begin{array}{lll}
T_{11} & T_{12} & T_{13} \\
T_{21} & T_{22} & T_{23} \\
T_{31} & T_{32} & T_{33}
\end{array}\right) \\
=\frac{1}{2}\left(\begin{array}{ccc}
|a+b|^{2} & (a+b)(a-b)^{*} & 2(a+b) c^{*} \\
(a-b)(a+b)^{*} & |a-b|^{2} & 2(a-b) c^{*} \\
2 c(a+b)^{*} & 2 c(a-b)^{*} & 4|c|^{2}
\end{array}\right) .
\end{gathered}
$$

\section{A. Polarization Orientation Angle (POA)}

The polarization orientation angle (POA) is a good estimator of the azimuth angle of the target [6]. The POA, $\theta$, is estimated as

$$
\theta=\frac{1}{4} \tan ^{-1} \frac{2 \operatorname{Re}\left(T_{23}\right)}{T_{22}-T_{33}},\left(-\frac{\pi}{4} \leq \theta \leq \frac{\pi}{4}\right)
$$

The angle $\theta$ is determined by requiring that the wall normal be parallel to the sensor's ground range direction, which is equivalent to minimizing $T_{33}(\theta)$.

\section{B. Four-component Decomposition}

Four-component decomposition is a method of decomposing the observed backscattering into four components calculated from the coherency matrix [7], [8]. Applying the four-component decomposition method to the full PolSAR data gives the surface scattering power $(P s)$, the double-bounce scattering power $(P d)$, the volume scattering power $(P v)$, and the helix scattering power $(P c)$. However, these components are also sensitive to POA.

Yamaguchi et al. [9] proposed an algorithm that rotates the coherency matrix by the POA in order to reduce the dependence of the components on the relative azimuth. A rotation is applied to the coherency matrix:

$$
T(\theta)=\left(\begin{array}{lll}
T_{11}(\theta) & T_{12}(\theta) & T_{13}(\theta) \\
T_{21}(\theta) & T_{22}(\theta) & T_{23}(\theta) \\
T_{31}(\theta) & T_{32}(\theta) & T_{33}(\theta)
\end{array}\right)=\left[R_{p}(\theta)\right][T]\left[R_{p}(\theta)\right]^{\dagger}
$$

Here, $\dagger$ denotes complex conjugation and transposition, and $R_{p}(\theta)$ is the rotation matrix given by

$$
\left[R_{p}(\theta)\right]=\left(\begin{array}{ccc}
1 & 0 & 0 \\
0 & \cos 2 \theta & \sin 2 \theta \\
0 & -\sin 2 \theta & \cos 2 \theta
\end{array}\right) .
$$

However, a dependence remains even after this correction [10], and removal of the remaining angular effects is a nontrivial problem.

\section{ANALYSIS OF EXPERIMENTAL DATA}

On September 20 and 21, 2011, an experiment was carried out in the anechoic radio wave chamber at the Wave Engineering Laboratory of the Department of Information Engineering, Faculty of Engineering, Niigata University, Japan. The main purpose of this experiment was to examine how the azimuth angle and the density of targets affect the four components of scattering power. A polarimetric measurement system capable of synthetic aperture processing was used. The wave frequency was X-band (10 GHz), antenna height was 260 $\mathrm{cm}$, and the incidence angle was $45^{\circ}$. Six concrete rectangular blocks with $10 \mathrm{~cm} \times 10 \mathrm{~cm}$ base area and $40 \mathrm{~cm}$ height were arranged on a $3 \times 2$ grid. The azimuth angle of the target 


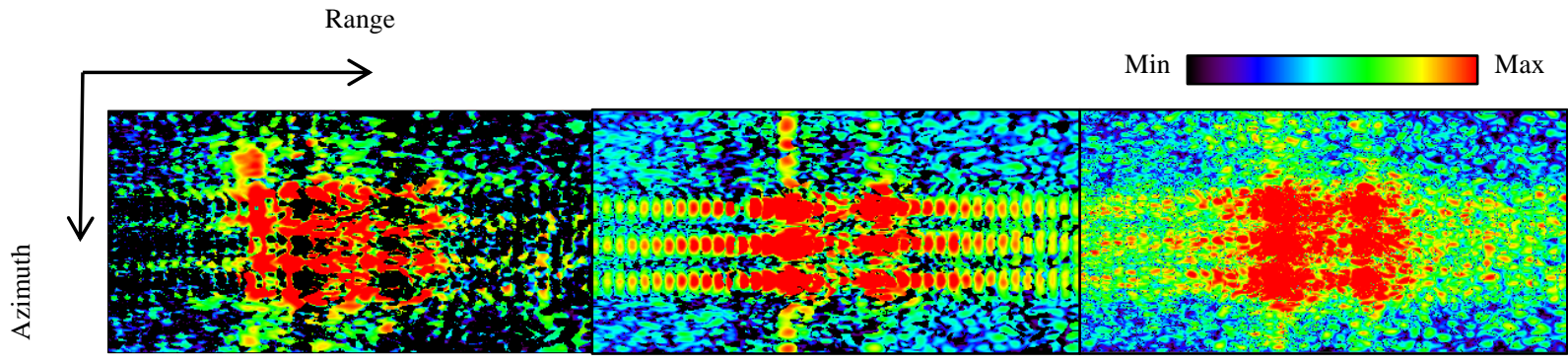

(a) $[-80,-24 \mathrm{~dB}]$

(b) $[-80,-8 \mathrm{~dB}]$

(c) $[-80,-26 \mathrm{~dB}]$

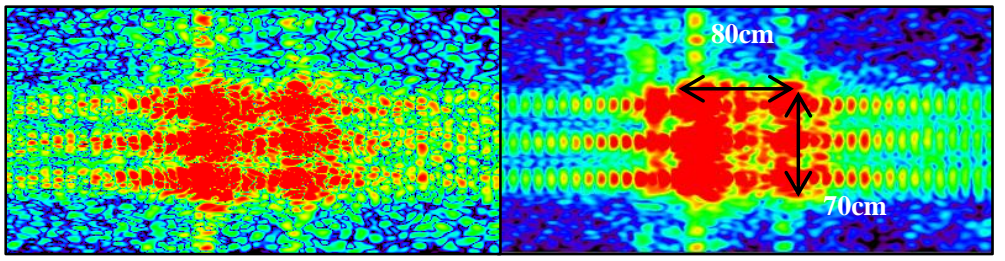

(d) $[-80,-19 \mathrm{~dB}]$

(e) $[-74,-8 \mathrm{~dB}]$

Fig. 2. Decomposed X-band experimental data at a POA of $0^{\circ}$, and distance $20 \mathrm{~cm} \times 60 \mathrm{~cm}$. (a) Ps, (b) Pd, (c) Pv, (d) Pc, and (e) TP.

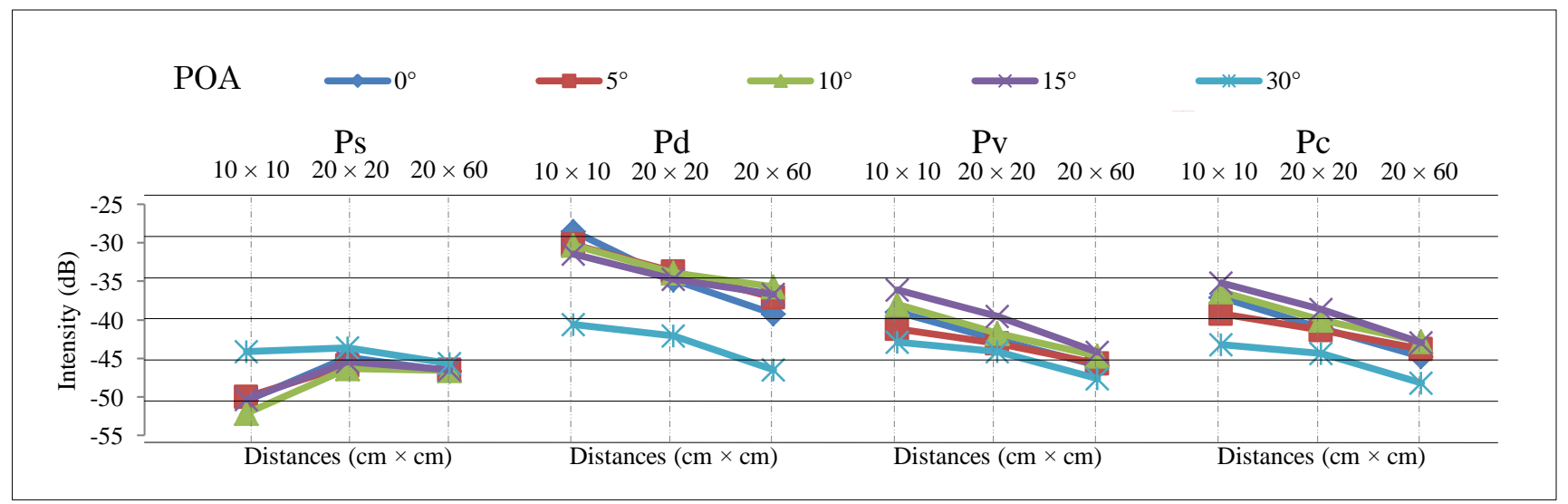

Fig. 3. Relation between density and power components derived by four-component decomposition of X-band experimental data

structure is defined as $0^{\circ}$ when the normal to the sides of the blocks is parallel to the sensor's ground range direction. First, measurements were made with the structure at $0^{\circ}$; then the whole structure was rotated clockwise. Measurements were made three times at azimuth angles of $0^{\circ}, 5^{\circ}, 10^{\circ}, 15^{\circ}$, and $30^{\circ}$, with distances of $10 \mathrm{~cm} \times 10 \mathrm{~cm}, 20 \mathrm{~cm} \times 20 \mathrm{~cm}$, and $20 \mathrm{~cm} \times 60 \mathrm{~cm}$ between the blocks.

Fig. 2 shows decomposed images of the four components and total power $(T P)$ at a POA of $0^{\circ}$ with distances $20 \mathrm{~cm} \times 60 \mathrm{~cm}$. Fig. 3 shows plots of the four power components versus distances $(10 \mathrm{~cm} \times 10 \mathrm{~cm}, 20 \mathrm{~cm} \times 20 \mathrm{~cm}$, $20 \mathrm{~cm} \times 60 \mathrm{~cm}$ ) between blocks at azimuth angles $0^{\circ}, 5^{\circ}, 10^{\circ}$, $15^{\circ}$, and $30^{\circ}$. The four components were calculated from the rotated coherency matrix. The component $P c$ is recalculated after the four-component decomposition process finishes. The original $P c$ seems to be mainly noise, so it is difficult to use it for image analysis. By recalculating $P c$ at the end of the process, the component shows meaningful scattering, though the sum of the four components including the recalculated $P c$ exceeds $T P$.

$P d, P v$, and $P c$ decrease as the distances between blocks become larger, in other words, as the structure density becomes lower; in contrast, $P s$ increases. However, the intensity change pattern of $P s$ is not as clear as that of the other components. Furthermore, each component depends on the azimuth angle even after rotation of the coherency matrix.

Overall, this experimental data analysis revealed that the four components depend on both the azimuth angle (POA in the case of space-borne PolSAR data) and structure density. Fig. 3 shows the intensity change patterns against structure density for each azimuth angle. Measurements were made at fixed azimuth angles in this experiment, which means various target structures with different azimuth angles are not mixed at any time. Therefore, POA correction is not necessary for each measurement. POA correction is a method of filling intensity gaps between target structures with different azimuth angles. However, if experimental results with different azimuth angles are compared with each other, POA correction should be done.

Generally, space-borne PolSAR data contains various target structures with different azimuth angles. Therefore, in order to fill the intensity gaps among these structures, POA correction is an essential process. 


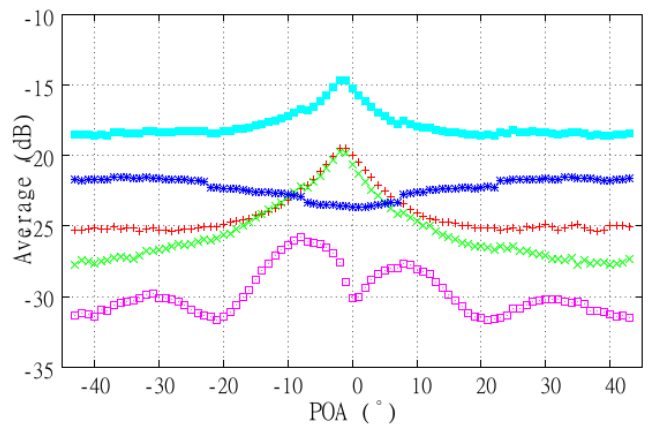

(a)

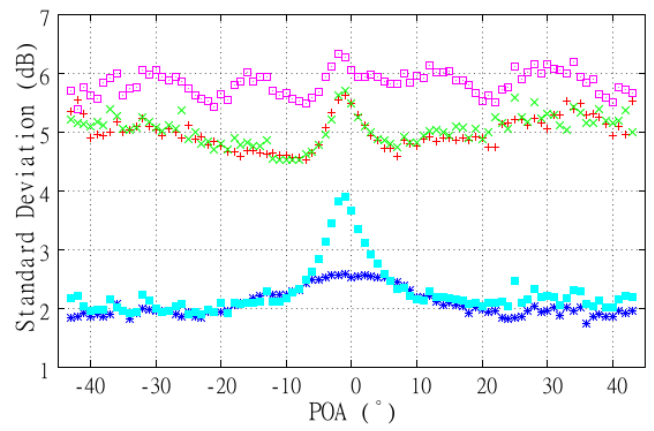

(b)

Fig. 4. Relation between POA and power components derived by four-component decomposition of a PALSAR image. (a) Average and (b) standard deviation, in urban areas. Red points denote Ps, green points denote Pd, navy blue points denote Pv, pink points denote Pc, and sky blue points denote TP.

\section{METHODS}

The four power components depend on the azimuth angle, and respond to the structure density (Fig. 3). Fig. 4 shows the average and standard deviation of each power component versus POA for urban areas in a PolSAR (Advanced Land Observing Satellite (ALOS)/Phased Array type L-band SAR (PALSAR)) image. Here, $P c$ is recalculated as it was for the $\mathrm{X}$-band experimental data in Section III. Hereinafter, $P c$ should be taken to mean the recalculated $P c$, not the original. In space-borne PolSAR images, the four power components depend on POA like they do in the X-band experimental data. POA dependence is seen especially in urban areas. Therefore, POA correction is necessary when analyzing urban areas using SAR images. After this angular effect is removed, the SAR image of urban areas contains effects mainly caused by building height and building area. Thus, the POA correction leads to urban density estimation. In this study, a POA correction algorithm is proposed. The POA correction method itself is the normalization of scattering power components. The POA correction is conducted after urban area extraction using PolSAR images [5]. The proposed algorithm consists of two steps. The first step is the extraction of homogeneous-POA city districts. The second step is the normalization of scattering power components in each POA space. Fig. 5 shows a flowchart of the proposed algorithm. In this study, Lee's sigma filter is applied to POLSAR images as a speckle filter [8]. The local window size for the filtering was set to $5 \times 5$ in this study. In the process of urban area extraction, a $3 \times 3$ boxcar filter was applied to the coherency matrix. The boxcar filter is effective in removing speckle noise but blurs an image quite substantially. However, in urban density estimation, preserving a target signature is a top priority, thus Lee's sigma filter with the smallest window size $5 \times 5$ was selected.

\section{A. Extraction of Homogeneous-POA City Districts}

The main purpose of this step is to discriminate high intensity orthogonal building areas from low intensity orthogonal building areas. The four components depend on POA (Fig. 4). However, even if two pixels' POAs are almost same, their scattering intensities can be very different, especially in

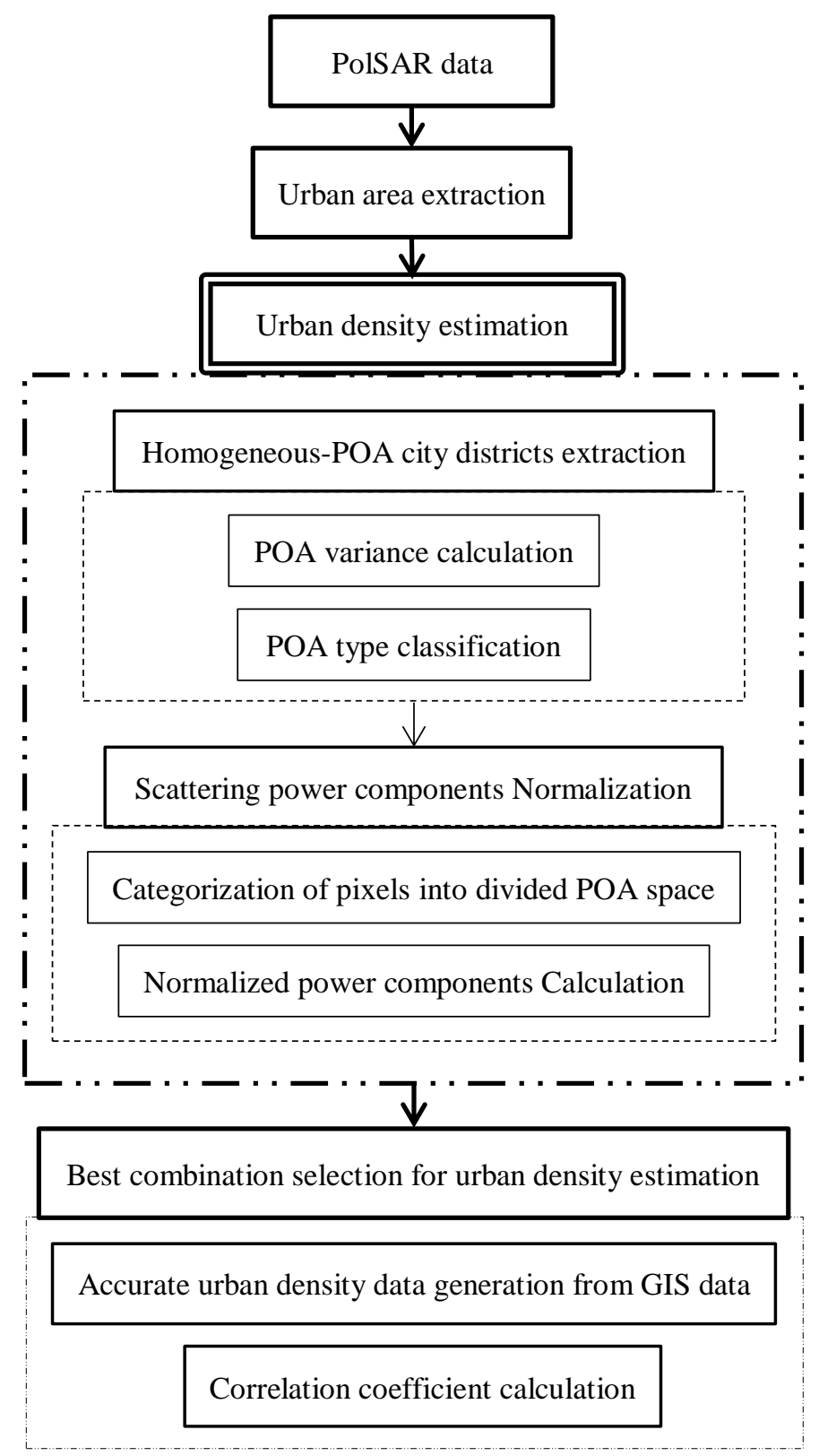

Fig. 5. Flowchart of the proposed algorithm. 


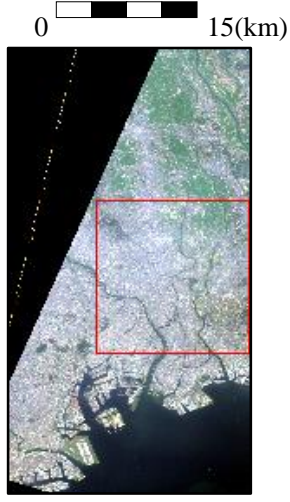

(a)

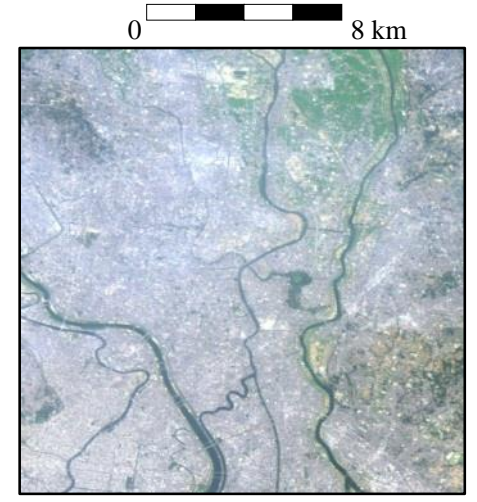

(b)

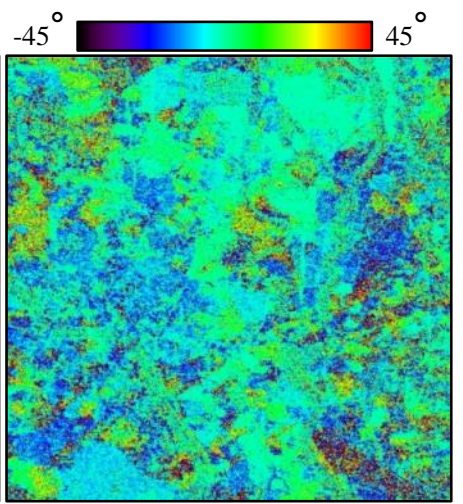

(d)

(c)

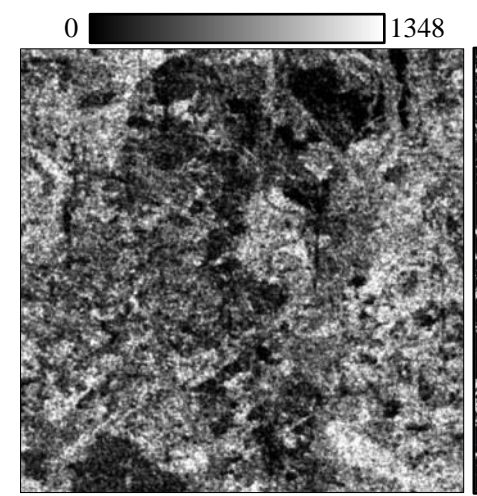

(e) (f)

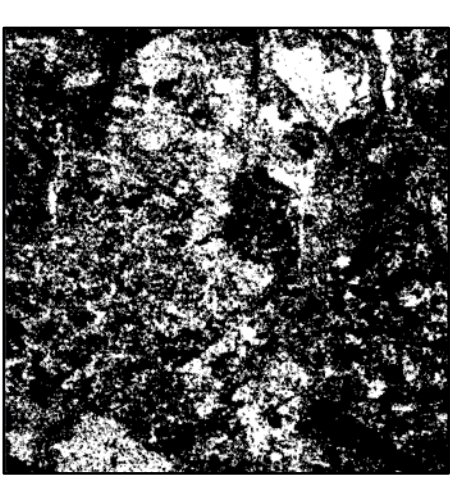

Fig. 6. Relation between POA and TP in orthogonal building areas. (a) Study area in Tokyo and Saitama, Japan, (b) AVNIR-2 image, (c) TP, (d) POA map, (e) POA variance, and (f) homogeneous and heterogeneous POA map (white pixels denote homogeneous POA and black pixels denote heterogeneous POA).

orthogonal building areas. This difference occurs because some pixels are homogeneous-POA pixels and others are heterogeneous-POA pixels (Figs. 6(c) and (d)). Here, homogeneous-POA and heterogeneous-POA pixels are defined as follows. If the reference pixel's POA and neighboring pixels' POAs are almost same, the reference pixel is considered to be a homogeneous POA pixel. In contrast, if there is a large difference between the POAs of the reference pixel and the neighboring pixels, this case is defined as a heterogeneous POA pixel. POA variance is calculated as follows.

$$
\operatorname{Var}(i, j)=\frac{1}{N_{m n}} \sum_{m} \sum_{n}\left(\theta(m, n)-\mu_{\theta}(i, j)\right)^{2}
$$

where $\operatorname{Var}(i, j)$ is the POA variance of the $(i, j)$ pixel, $N_{m n}$ is the pixel count in the local Lee sigma filtering window of the $(i$, $j$ ) pixel, $\theta$ is the POA, $(m, n)$ indicates the location of pixels lying within the local window, and $\mu_{\theta}(i, j)$ is the average POA within the local window. The local window type and size used to calculate the reference pixel's POA variance are the same as those adopted in the process of Lee sigma filtering for the reference pixel. This calculation is done for all pixels of an image. Fig. 6(e) shows the results of POA variance calculation for Tokyo, Japan.

The POA type $H(i, j)$ of pixel $(i, j)$ is given by

$$
H(i, j)= \begin{cases}\text { HomoPOA } & (\operatorname{Var}(i, j)<\text { Threshold }) \\ \text { HeteroPOA } & (\operatorname{Var}(i, j)>\text { Threshold })\end{cases}
$$

The threshold to determine whether pixels are homogeneous or heterogeneous is set at $185.5 \mathrm{deg}^{2}$, that is equivalent to approximately $13.6 \mathrm{deg}$ standard deviation of POA. This value is determined by considering orthogonal building areas of Tokyo and Sapporo images. After manually determining regions of interest (ROIs) of homogeneous orthogonal building areas for Tokyo and Sapporo areas, the thresholds, including 95\% of all pixels belonging to the ROIs, were 188 (Tokyo) and 183 (Sapporo). So, in this study, the average of the two study areas' thresholds, 185.5, was used (Fig. 6(f)). The ROIs were limited to homogeneous orthogonal building areas because this step is focused on extracting homogeneous orthogonal building areas which show extraordinarily high intensity. The ROIs were manually obtained by checking if a PolSAR image shows extraordinarily high intensity, and optical images were used as a reference. Even in homogeneous orthogonal building areas, intensity variance is very different from one image to another, which means intensity is not a useful index in this step and cannot be universalized. In contrast, the range of POA variance is much smaller than that of intensity because POA ranges around $-10^{\circ}$ to $10^{\circ}$ in homogeneous orthogonal areas. Therefore, the threshold for discriminating homogeneous orthogonal building areas from heterogeneous orthogonal and other building areas is not so different in each image. By averaging the thresholds of some study areas, the averaged threshold, 185.5 in this case, can be universalized for other images obtained by the same sensor (ALOS / PALSAR).

Fig. 7 shows the average and the standard deviation of the four components and TP separately for homogeneous and heterogeneous POA areas in each POA space. Particularly around POAs of $-10^{\circ}$ to $10^{\circ}$, homogeneous and heterogeneous POA areas show large differences in power components' scattering intensity for all components apart from $P v$. At POAs smaller than $-20^{\circ}$ and larger than $20^{\circ}$, the average and the standard deviation of homogeneous POA areas vary randomly because the number of pixels belonging to the POA spaces is 


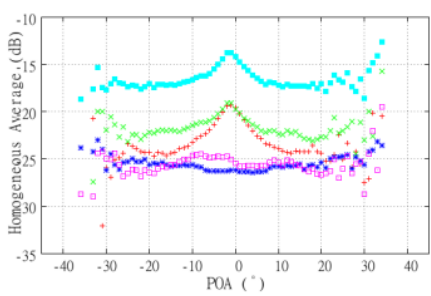

(a)

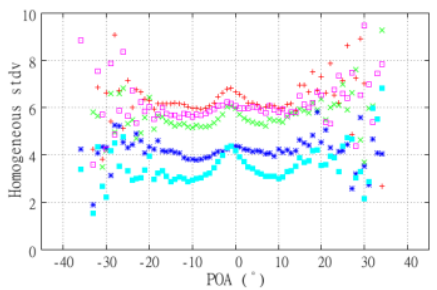

(c)

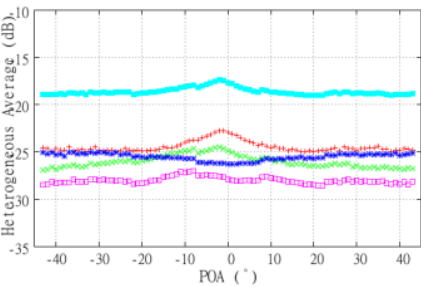

(b)

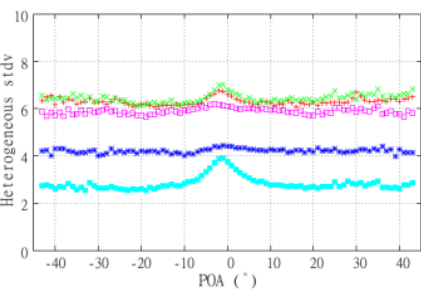

(d)

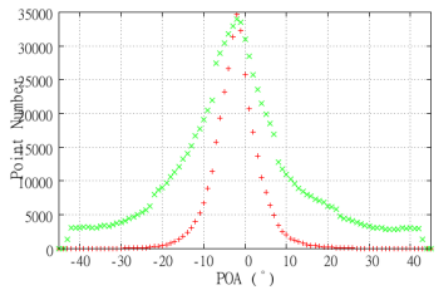

(e)

Fig. 7. Average and standard deviation plotted against POA in both homogeneous and heterogeneous POA areas. (a) Average and (c) standard deviation for homogeneous POA areas; (b) average and (d) standard deviation for heterogeneous POA areas. (For both types of area red points denote Ps, green points denote $\mathrm{Pd}$, navy blue points denote $\mathrm{Pv}$, pink points denote $\mathrm{Pc}$, and sky blue points denote TP.) (e) Point number in each POA space (red points denote homogeneous POA and green points denote heterogeneous POA).

very small (Fig. 7(e)). Homogeneous POA areas are seen especially in orthogonal building areas.

Comparison of the PolSAR image and the POA variance map after binarization shows that homogeneous-POA city districts are well related to orthogonal building areas whose scattering intensity is extraordinarily high.

\section{B. Normalization of Scattering Power Components in Each POA Interval}

As mentioned above, the four components depend on POA. Thus, urban density estimation without the POA correction is challenging. We show that the influence of POA can be removed by normalizing scattering power components in each POA space. The procedure is the following. First, the whole POA space $\left(-45^{\circ}\right.$ to $\left.45^{\circ}\right)$ is divided into $1^{\circ}$ intervals (e.g., the POA space around $0^{\circ}$ is $-0.5^{\circ}$ to $0.5^{\circ}$ ). Next, each pixel of a SAR image is categorized into one of the POA intervals according to its POA.

Then, in each POA interval, the average and the standard deviation of each power component's scattering intensity in urban areas are calculated separately for homogeneous and heterogeneous POA areas after conversion of the intensity into
dB (Fig. 7). Finally, each power component's scattering intensity is normalized for all pixels in each POA interval, as follows.

$$
\begin{aligned}
T_{\text {comp }}(i, j) \approx & T_{\text {comp }}(i, j, \phi, H) \\
& =\frac{P_{c o m p}(i, j, \phi, H)-\mu_{c o m p}(\phi, H)}{\sigma_{c o m p}(\phi, H)}
\end{aligned}
$$

where $T$ is the normalized scattering intensity, $P$ is the original scattering intensity, $\mu$ and $\sigma$ are the average and the standard deviation of the scattering intensity, which are calculated separately for homogeneous-POA and heterogeneous-POA areas in each POA interval, $(i, j)$ indicates the location of the reference pixel, and $\phi$ is the POA interval to which the $(i, j)$ pixel belongs. The subscript comp, which is an abbreviation of component, denotes one of the four power components ( $s$ : surface, $d$ : double bounce, $v$ : volume, $c$ : helix). Hereinafter, descriptions like " $T d+v$ " will appear in this paper. This means that the sum of $P d$ and $P v, " P d+v$ ", is normalized according to equation (8). It should be noted that, for example, $T d+v$ means normalized $P d+v$, not the simple sum of $T d$ and $T v$.

Generally, the scattering intensity has a log-normal distribution. However, if a SAR image includes orthogonal building areas, the scattering intensity from orthogonal building areas is extraordinarily high. Thus the frequencies in the right hand lobe of the scattering intensity histogram are high, and cannot be ignored, causing a distortion of the histogram. This is why, in the extraction of homogeneous-POA city districts (Section IV-A), orthogonal building areas are separated from other urban areas. Moreover, normalization of scattering intensity is attempted separately for these two types of urban areas. The threshold of the maximum deviation was set to $3 \sigma$ in this study, and finally the value of $\mathrm{T}$ was converted so that it ranges from 0 to 1 . Supposing normal distribution, pixels of $99.7 \%$ out of all pixels belonging to the distribution are included within $\pm 3 \sigma .99 .7 \%$ is considered to be sufficient to contain almost all pixels belonging to the distribution, thus this threshold was set in this study.

Fig. 8 shows POA correction results for the four components and $T P . T d, T v$, and $T c$ have almost no POA dependence. However, $T s$ still has some POA dependence. The calculated $P s$ is mostly 0 in oblique building areas, even after the four-component decomposition with rotation of the coherency matrix [11]. In contrast, $P S$ is extremely high in orthogonal building areas. Therefore, $P s$ is unstable especially in urban areas. The proposed method corrects for this difference in each POA interval's scattering intensity. When the scattering intensity is 0 in a POA interval, the effect of the proposed method cannot be seen. Moreover, the proposed normalization assumes that the target intensity histogram has a normal distribution after conversion of the intensity into $\mathrm{dB}$. However, $P s$ only has a non-symmetrical scattering intensity histogram for each POA interval even belonging to the homogeneous POA type, which means the proposed normalization cannot be 


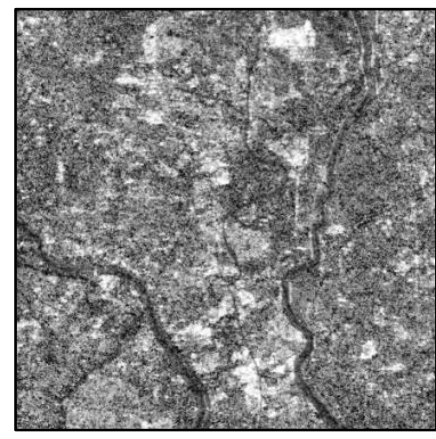

(a)

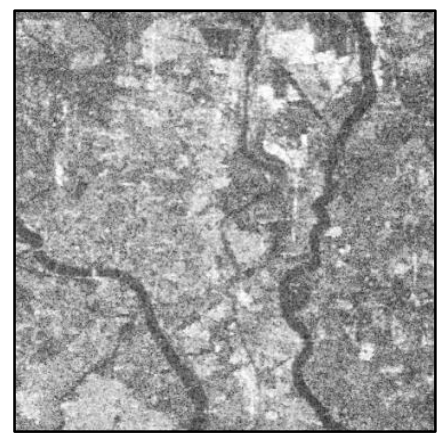

(c)

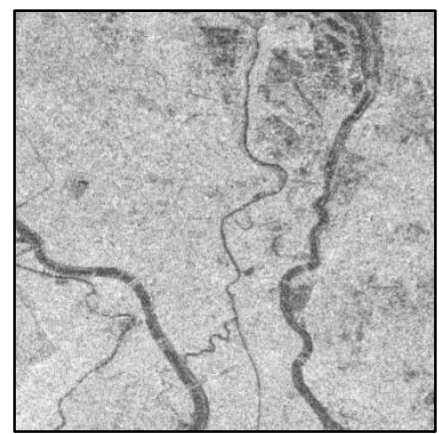

(e)

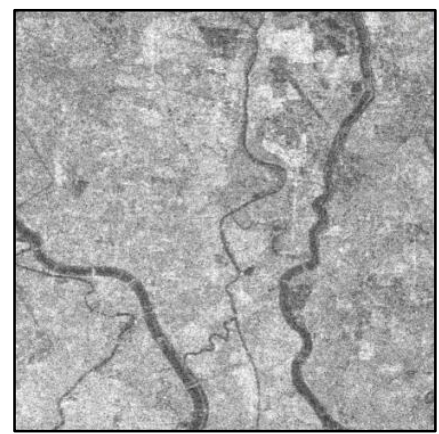

(g)

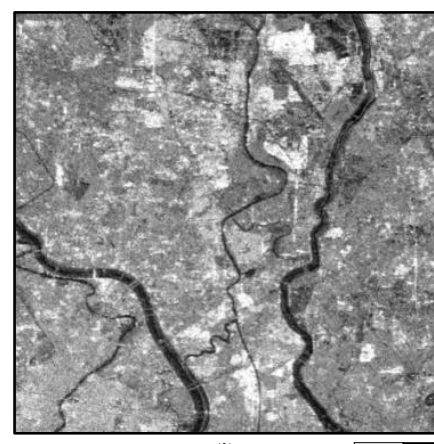

(i)

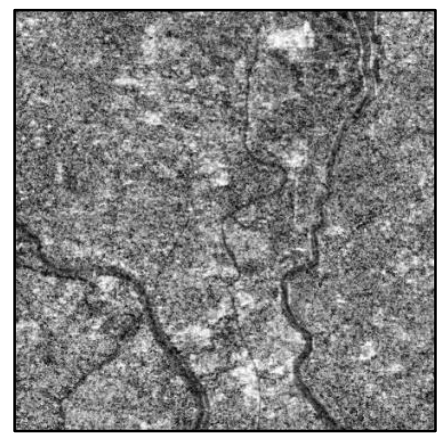

(b)

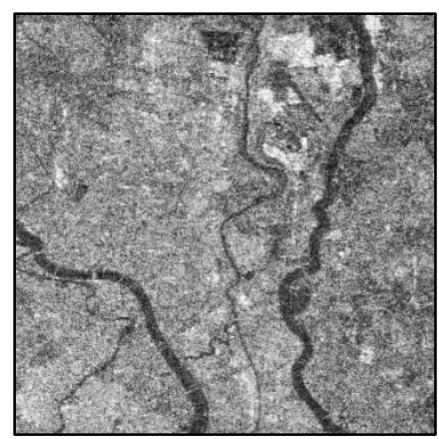

(d)

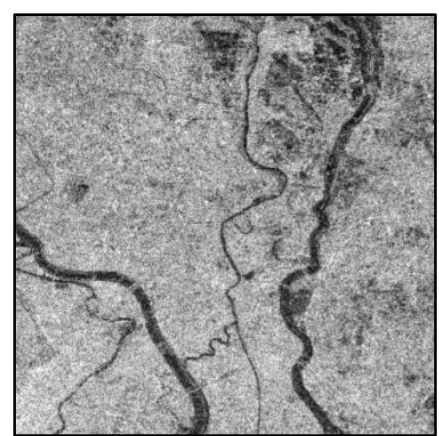

(f)

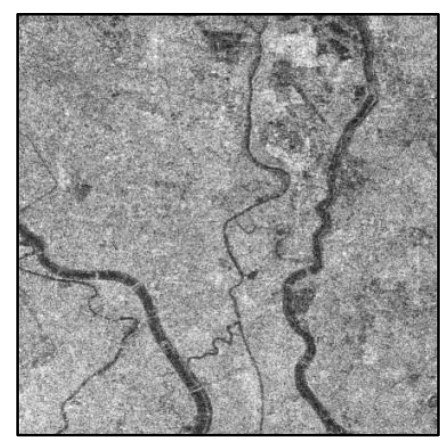

(h)

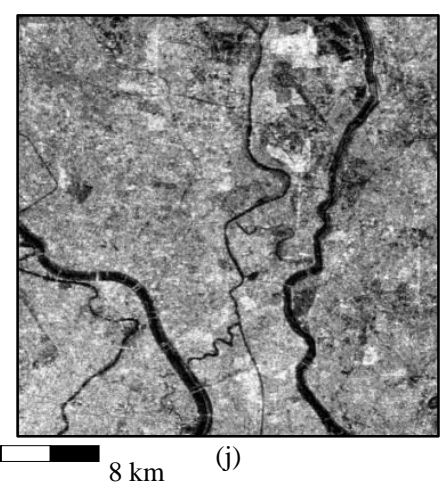

applied properly. In conclusion, considering the results shown in Fig. 3, Ps only has a weak negative correlation with the structure density. Thus, $P s$ should not be used for urban density estimation because of the above-mentioned facts. In the next section, an assessment of which combination of the scattering power components is the most effective for estimating urban density is made.

\section{EXPERIMENTAL RESULTS AND DISCUSSION}

In this study, fully polarimetric ALOS/PALSAR level 1.1 (L1.1) data were used. Furthermore, ALOS/Advanced Visible and Near Infrared Radiometer type 2 (AVNIR-2) optical sensor data were used as a reference. Accurate information on urban density was obtained from Zmap-TOWN II (ZENRIN) data, which are residential maps of Japan.

\section{A. Accurate Urban Density Data Generation Using GIS Data}

Accurate urban density data for the Tokyo metropolitan area, Japan, are generated from Zmap-TOWN II (GIS) data with reference to [12]. Two types of urban density are defined in this study. One is the building-to-land ratio, and the other is the floor area ratio. First, building polygon data are intersected by a mesh. Buildings lying across the mesh border line are divided into pieces by the border line. The mesh size used was $20 \mathrm{~m} \times 20 \mathrm{~m}$ which approximately corresponds to PALSAR's ground resolution after a multi-looking process. Building density is calculated as follows.

$$
\begin{gathered}
D_{\text {Building-to-Land }}(i, j)=\frac{\sum_{k=1}^{n} S_{k \text { th Building }}(i, j)}{S_{\text {Land }}(i, j)} \\
D_{\text {Floor }}(i, j)=\frac{\sum_{k=1}^{n} S_{k \text { th Building }}(i, j) \times F_{\text {kth Building }}(i, j)}{S_{\text {Land }}(i, j)}
\end{gathered}
$$

\section{(kth Building $\in(i, j)$ pixel $)$}

Here, $D$ is the estimated building density, $S$ is an area, and $F$ is a building floor. The pair $(i, j)$ is the location of the reference pixel, and $k$ denotes the $k$ th building included in the $(i, j)$ pixel. Figs. 9(a) and (d) show AVNIR-2 images, Figs. 9(b) and (e) show the building-to-land ratio, and Figs. 9(c) and (f) show floor area ratio in Tokyo metropolitan area. The building-to-land ratio is relatively high over the whole area of the image. However, the floor area ratio is high especially around the Imperial Palace located at the center of the images. Many tall buildings stand side by side, so the floor ratio was estimated to be very high. In contrast, the floor ratio in the other areas was estimated as being extraordinarily low. This is because, despite being numerous, the buildings in the other areas are not as tall as those standing around the Imperial Palace.

Fig. 8. Results of POA correction. (a) Ps, (b) Ts, (c) Pd, (d) Td, (e) Pv, (f) Tv, (g) Pc, (h) Tc, (i) TP, and (j) TP'. 


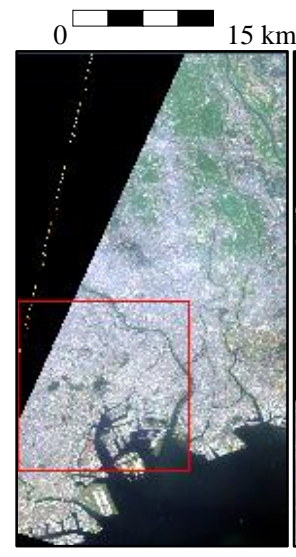

(a)

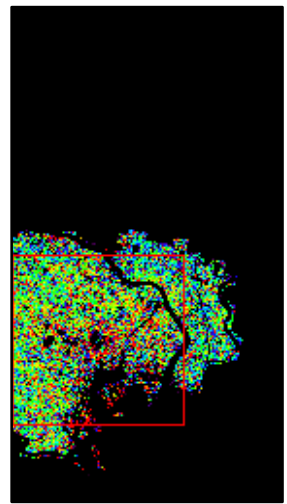

(e)

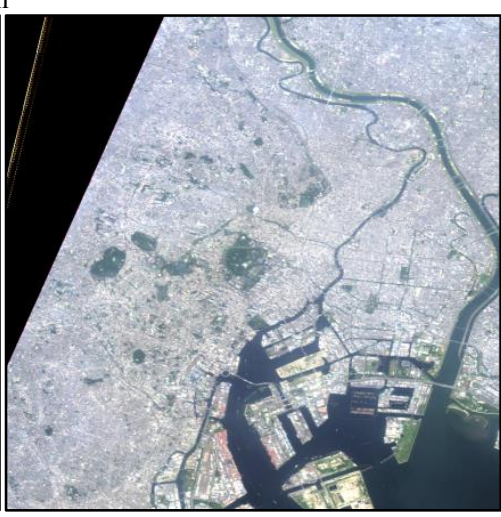

(b)

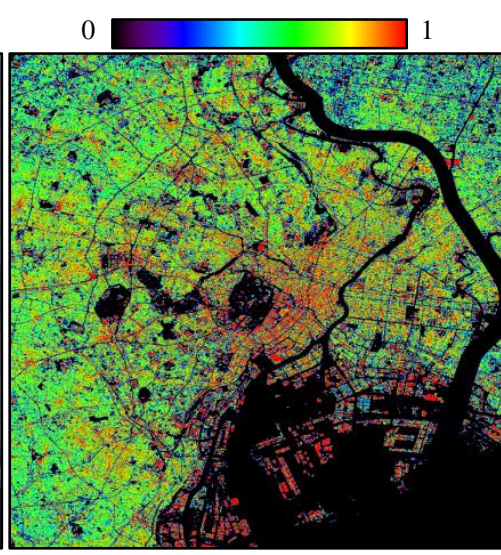

(c)

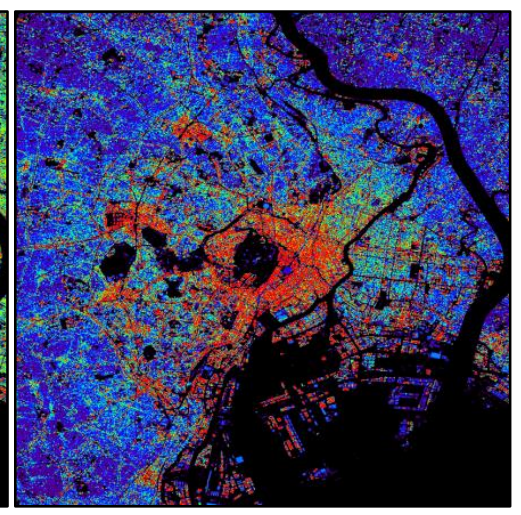

(d)

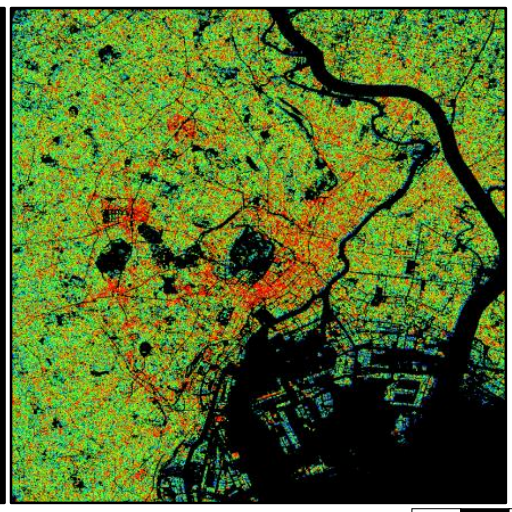

(f)

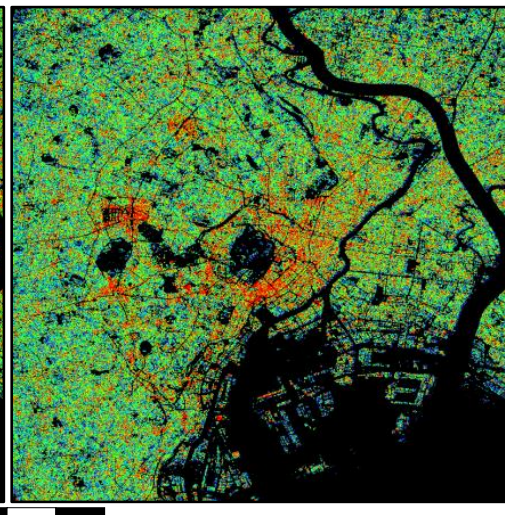

(g)

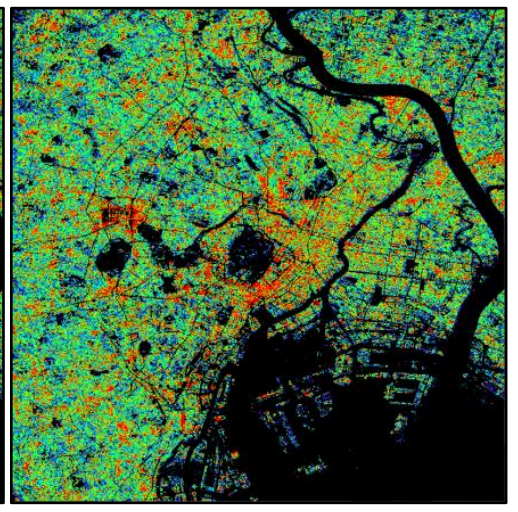

(h)

Fig. 9. Results of urban density estimation for the whole image: (a) AVNIR-2 image and (e) GIS data. Study area: (b) AVNIR-2 image, (c) building-to-land ratio, (d) floor area ratio, (f) $\mathrm{Tv}$, (g) $\mathrm{Tv}+\mathrm{c}$, and (h) $\mathrm{TP}^{\prime}$.

\section{B. Accuracy Assessment of Urban Density Estimation}

The best combination of the four components for estimating urban density is assessed by calculating correlation coefficients between the results from a PolSAR image and GIS data.

TABLE I shows the results of correlation coefficient calculations with and without POA correction for $100 \mathrm{~m}, 200 \mathrm{~m}$, $300 \mathrm{~m}$, and $500 \mathrm{~m}$ resolutions over the whole image and over orthogonal building areas only. The study area of orthogonal buildings is shown in Fig. 9(a). At first, a calculation for a resolution of approximately $24 \mathrm{~m}$, which is PALSAR's ground resolution after a multi-looking process, was attempted. However, the border between buildings and roads is not clear in PolSAR images because of the lack of data on roads caused by shadowing and layover effects of buildings in urban areas. As a result, the large difference of urban density between buildings and roads cannot be seen in a PALSAR image, which causes a large reduction in the correlation coefficient at scales of approximately $24 \mathrm{~m}$. Therefore, window sizes for the calculation were expanded to the resolutions mentioned above. TABLE I shows the results of the four components themselves and combinations of the three components excluding Ps. The reason why $P s$ was excluded from the combinations is that it still has a level of POA dependence even after the normalization described in Section IV. TP also still has POA dependence, mainly coming from asymmetry of the scattering intensity histogram.

On the whole, correlations with the building-to-land ratio are higher than those with the floor area ratio. This means urban density estimation from PolSAR images is better when using the former ratio than the latter one. Generally, SAR images contain effects of both building area and building height. However, the estimated floor area ratio is extraordinarily high around the Imperial Palace in the Tokyo metropolitan area. In contrast, the floor area ratio is calculated as being extremely low in the other areas where the buildings are not as tall. This is because the floor area ratio is affected by building height. Thus the floor area ratio changes dramatically between the area around the Imperial Palace and other areas. However, the building-to-land ratio only changes moderately. We conclude that urban density estimated from PolSAR images contains effects of both the building-to-land ratio and the floor area ratio, thus combinations of the four components which are high in both ratios are more accurate.

First, we assess the results achieved using the whole image. See TABLE I column (b). Correlations for all combinations become much higher from $100 \mathrm{~m}$ to $200 \mathrm{~m}$ and from $200 \mathrm{~m}$ to $300 \mathrm{~m}$. However, little improvement can be seen between 


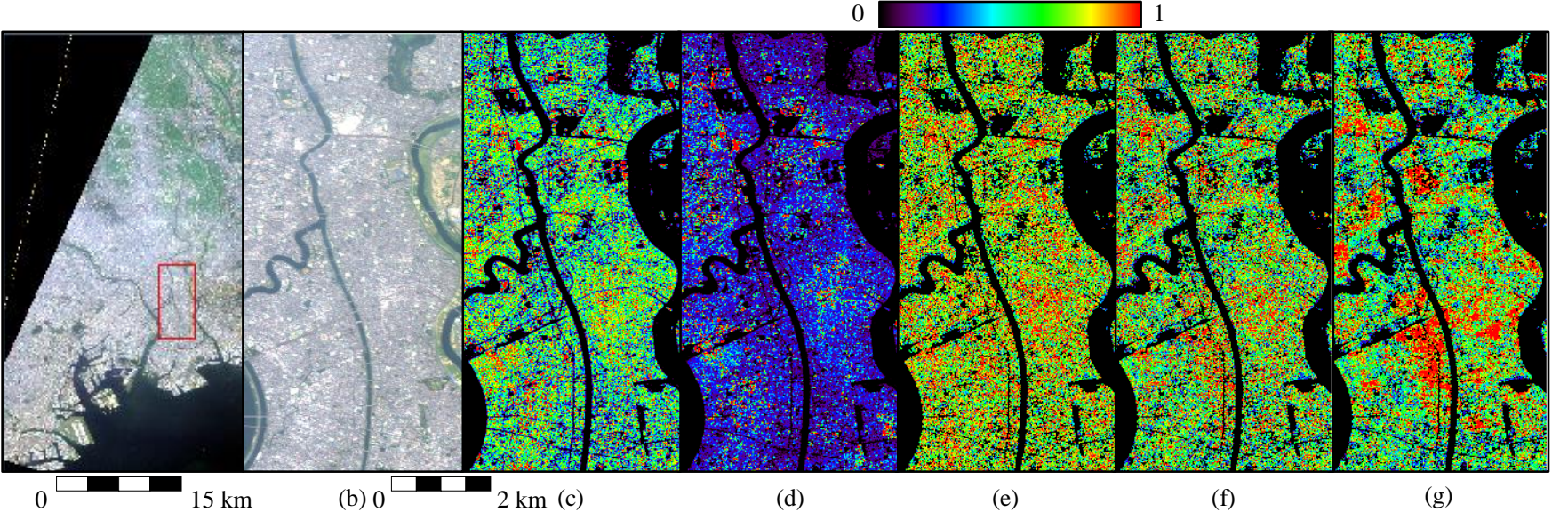

Fig. 10. Results of urban density estimation in orthogonal building areas. (a) Study area, (b) AVNIR-2 image, (c) building-to-land ratio, (d) floor area ratio, (e) Tv, (f) $\mathrm{Tv}+\mathrm{c}$, and $(\mathrm{g}) \mathrm{TP}^{\prime}$.

$300 \mathrm{~m}$ and $500 \mathrm{~m}$. Resolution sizes that are as small as possible are preferable. Therefore, $300 \mathrm{~m}$ is defined as the maximum size fo the accuracy assessment. Figs. 9 (g), (h), and (i) show $T v$, $T v+c$, and $T P^{\prime}$ (normalized $T P$ ), respectively. As can be seen from column (b) of TABLE I, $T P^{\prime}$ showed the highest correlation with building-to-land ratio, and $T v+c$ (normalized $P v+P c)$ showed the second highest correlation with both ratios. As for the four components themselves, Ts showed the lowest correlation and $T d$ showed low correlation with both ratios. $T v$ showed high correlation with the building-to-land ratio, and $T c$ showed high correlation with the floor area ratio.

Next, we assess the results achieved based only on orthogonal building areas where a strong POA dependence of each component is seen. Figs. 10 (e), (f), and (g) show $T v, T v+c$, and $T P^{\prime}$ in orthogonal building areas, respectively. As can be seen from column (d) of TABLE I, $T v+c$ showed the highest or second highest correlation with both ratios for all resolutions. $T v$ also showed high correlation with both ratios for small resolutions. As for the four components themselves, $T s, T d$, and $T c$ showed lower correlations with both ratios than $T v$. This shows that $T v$ has the least POA dependence of the four components. The effect of the proposed POA correction algorithm is assessed in the next subsection.

Based on these results, $T v+c$ is the most accurate combination. $T P^{\prime}$ showed high correlation for the whole image; however, the correlation was not especially high in orthogonal building areas bcause of the POA dependence of TP. Tv $+c$ is the most effective index for urban density estimation because it is robust, giving good estimates in a variety of areas. Fig. 11 shows building-to-land ratio, floor area ratio, and $T v+c$ for three mesh sizes $(100 \mathrm{~m}, 200 \mathrm{~m}$, and $300 \mathrm{~m})$. As can be seen from these figures, high urban density estimates from $T v+c$ are well linked to those from floor area ratio, especially around the Imperial Palace, which is the center of Tokyo, and Shinjuku City, which is a sub-center of Tokyo. Therefore, urban density estimated from PolSAR data properly includes the effects of building height. In other areas, urban density is also estimated almost correctly from PolSAR data, since there are large correlation coefficients with the building-to-land ratio. Although correlation increases with mesh size, in practical use the mesh size should be chosen case by case according to the purposes of the study.

\section{Assessment of the POA Correction Effect}

Now we assess the effect of POA correction algorithm. TABLE I also shows the urban density estimation accuracy with and without POA correction for both the whole image and only orthogonal building areas.

In the whole image case, all the components except for $P v$ were improved by the POA correction method. In particular, $P s$, $P d$, and $T P$ showed considerable improvement. Especially in orthogonal building areas, where a strong POA dependence is seen, correlation coefficients of some components were improved by more than 0.2 if it is on $300 \mathrm{~m}$ scale. Originally, $P v$ had less POA dependence than the other components, thus a large improvement of $P v$ was not seen when using the whole image. However, $T v+c$ which was judged as the most accurate combination in Section V-B was improved slightly. In contrast, an improvement of $P v$ was seen in orthogonal building areas with $200 \mathrm{~m}$ and $300 \mathrm{~m}$ mesh sizes. The other components, especially $P d$ and $T P$, were also improved by the POA correction method in orthogonal building areas.

Considering these improvements, the proposed POA correction algorithm is effective in orthogonal building areas, which exhibit a lot of POA dependence. The POA correction method is valid not only for urban density estimation but also for other PolSAR image analysis purposes because $P s, P d$ and $T P$ are particularly improved. Especially, $P d$ has less POA dependence after the POA correction than $P S$ and TP. This indicates that $T d$ and $T c$ could be useful components for other urban analyses in addition to $T v$ which originally has the least POA dependence of all components. The POA correction method is limited to PolSAR data. 
TABLE I

CORRELATION COEFFICIENTS OF ESTIMATED URBAN DENSITY BETWEEN SAR DATA AND GIS DATA

: highest correlation

(a) Whole image

without POA correction

sample $=46849$

\begin{tabular}{|l|r|r|}
\hline $100 \mathrm{~m}$ & building & \multicolumn{1}{l|}{ floor } \\
\hline $\mathrm{Ps}$ & 0.164 & -0.06 \\
\hline $\mathrm{Pd}$ & 0.227 & 0.144 \\
\hline $\mathrm{Pv}$ & 0.418 & 0.295 \\
\hline $\mathrm{Pc}$ & 0.354 & 0.272 \\
\hline $\mathrm{TP}$ & 0.36 & 0.214 \\
\hline $\mathrm{Pd}+\mathrm{v}$ & 0.353 & 0.269 \\
\hline $\mathrm{Pd}+\mathrm{c}$ & 0.32 & 0.248 \\
\hline $\mathrm{Pv}+\mathrm{c}$ & 0.425 & 0.315 \\
\hline $\mathrm{Pd}+\mathrm{v}+\mathrm{c}$ & 0.365 & 0.28 \\
\hline
\end{tabular}

sample $=12459$

\begin{tabular}{|l|r|r|}
\hline $200 \mathrm{~m}$ & building & floor \\
\hline $\mathrm{Ps}$ & 0.275 & -0.052 \\
\hline $\mathrm{Pd}$ & 0.387 & 0.247 \\
\hline $\mathrm{Pv}$ & 0.621 & 0.435 \\
\hline $\mathrm{Pc}$ & 0.557 & 0.407 \\
\hline $\mathrm{TP}$ & 0.541 & 0.328 \\
\hline $\mathrm{Pd}+\mathrm{v}$ & 0.54 & 0.396 \\
\hline $\mathrm{Pd}+\mathrm{c}$ & 0.499 & 0.367 \\
\hline $\mathrm{Pv}+\mathrm{c}$ & 0.621 & 0.446 \\
\hline $\mathrm{Pd}+\mathrm{v}+\mathrm{c}$ & 0.551 & 0.405 \\
\hline
\end{tabular}

sample $=5842$

\begin{tabular}{|l|r|r|}
\hline $300 \mathrm{~m}$ & building & \multicolumn{1}{l|}{ floor } \\
\hline $\mathrm{Ps}$ & 0.34 & -0.022 \\
\hline $\mathrm{Pd}$ & 0.479 & 0.31 \\
\hline $\mathrm{Pv}$ & 0.692 & 0.488 \\
\hline $\mathrm{Pc}$ & 0.647 & 0.47 \\
\hline $\mathrm{TP}$ & 0.618 & 0.388 \\
\hline $\mathrm{Pd}+\mathrm{v}$ & 0.62 & 0.451 \\
\hline $\mathrm{Pd}+\mathrm{c}$ & 0.586 & 0.427 \\
\hline $\mathrm{Pv}+\mathrm{c}$ & 0.688 & 0.495 \\
\hline $\mathrm{Pd}+\mathrm{v}+\mathrm{c}$ & 0.629 & 0.459 \\
\hline
\end{tabular}

sample $=2172$

\begin{tabular}{|l|r|r|}
\hline $500 \mathrm{~m}$ & building & \multicolumn{1}{l|}{ floor } \\
\hline $\mathrm{Ps}$ & 0.402 & 0.006 \\
\hline $\mathrm{Pd}$ & 0.553 & 0.359 \\
\hline $\mathrm{Pv}$ & 0.716 & 0.518 \\
\hline $\mathrm{Pc}$ & 0.676 & 0.5 \\
\hline $\mathrm{TP}$ & 0.675 & 0.438 \\
\hline $\mathrm{Pd}+\mathrm{v}$ & 0.658 & 0.484 \\
\hline $\mathrm{Pd}+\mathrm{c}$ & 0.632 & 0.466 \\
\hline $\mathrm{Pv}+\mathrm{c}$ & 0.718 & 0.525 \\
\hline $\mathrm{Pd}+\mathrm{v}+\mathrm{c}$ & 0.671 & 0.494 \\
\hline
\end{tabular}

sample $=12459$

sample $=2172$ (b) Whole image

with POA correction

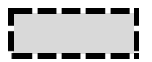

(c) Orthogonal building area without POA correction

sample $=4503$

sample $=46849$
\begin{tabular}{|l|r|r|}
\hline $100 \mathrm{~m}$ & \multicolumn{1}{|c|}{ building } & floor \\
\hline $\mathrm{Ts}$ & 0.243 & -0.01 \\
\hline $\mathrm{Td}$ & 0.309 & 0.237 \\
\hline $\mathrm{Tv}$ & 0.412 & 0.291 \\
\hline $\mathrm{Tc}$ & 0.379 & 0.306 \\
\hline $\mathrm{TP}$ & 0.44 & 0.284 \\
\hline $\mathrm{Td}+\mathrm{v}$ & 0.395 & 0.319 \\
\hline $\mathrm{Td}+\mathrm{c}$ & 0.381 & 0.318 \\
\hline $\mathrm{Tv}+\mathrm{c}$ & 0.426 & 0.324 \\
\hline $\mathrm{Td}+\mathrm{v}+\mathrm{c}$ & 0.407 & 0.33 \\
\hline
\end{tabular}

\begin{tabular}{|l|r|r|}
\hline $200 \mathrm{~m}$ & \multicolumn{1}{|c|}{ building } & \multicolumn{1}{l|}{ floor } \\
\hline $\mathrm{Ts}$ & 0.405 & 0.038 \\
\hline $\mathrm{Td}$ & 0.508 & 0.38 \\
\hline $\mathrm{Tv}$ & 0.622 & 0.435 \\
\hline $\mathrm{Tc}$ & 0.594 & 0.455 \\
\hline $\mathrm{TP}$ & 0.638 & 0.421 \\
\hline $\mathrm{Td}+\mathrm{v}$ & 0.594 & 0.461 \\
\hline $\mathrm{Td}+\mathrm{c}$ & 0.581 & 0.461 \\
\hline $\mathrm{Tv}+\mathrm{c}$ & 0.629 & 0.468 \\
\hline $\mathrm{Td}+\mathrm{v}+\mathrm{c}$ & 0.605 & 0.47 \\
\hline
\end{tabular}

sample $=5842$
\begin{tabular}{|l|r|r|}
\hline $300 \mathrm{~m}$ & \multicolumn{1}{l|}{ building } & \multicolumn{1}{l|}{ floor } \\
\hline $\mathrm{Ts}$ & 0.496 & 0.1 \\
\hline $\mathrm{Td}$ & 0.603 & 0.446 \\
\hline $\mathrm{Tv}$ & 0.708 & 0.5 \\
\hline $\mathrm{Tc}$ & 0.686 & 0.52 \\
\hline $\mathrm{TP}$ & 0.722 & 0.49 \\
\hline $\mathrm{Td}+\mathrm{v}$ & 0.679 & 0.52 \\
\hline $\mathrm{Td}+\mathrm{c}$ & 0.668 & 0.52 \\
\hline $\mathrm{Tv}+\mathrm{c}$ & 0.712 & 0.526 \\
\hline $\mathrm{Td}+\mathrm{v}+\mathrm{c}$ & 0.689 & 0.529 \\
\hline
\end{tabular}

\begin{tabular}{|l|r|r|}
\hline $500 \mathrm{~m}$ & \multicolumn{1}{|c|}{ building } & \multicolumn{1}{l|}{ floor } \\
\hline $\mathrm{Ts}$ & 0.563 & 0.145 \\
\hline $\mathrm{Td}$ & 0.657 & 0.489 \\
\hline $\mathrm{Tv}$ & 0.718 & 0.52 \\
\hline $\mathrm{Tc}$ & 0.706 & 0.546 \\
\hline $\mathrm{TP}$ & 0.759 & 0.555 \\
\hline $\mathrm{Td}+\mathrm{v}$ & 0.703 & 0.545 \\
\hline $\mathrm{Td}+\mathrm{c}$ & 0.702 & 0.553 \\
\hline $\mathrm{Tv}+\mathrm{c}$ & 0.741 & 0.582 \\
\hline $\mathrm{Td}+\mathrm{v}+\mathrm{c}$ & 0.712 & 0.554 \\
\hline
\end{tabular}

\begin{tabular}{|l|r|r|}
\hline $100 \mathrm{~m}$ & \multicolumn{1}{|c|}{ building } & floor \\
\hline $\mathrm{Ps}$ & 0.163 & -0.012 \\
\hline $\mathrm{Pd}$ & 0.321 & 0.162 \\
\hline $\mathrm{Pv}$ & 0.557 & 0.305 \\
\hline $\mathrm{Pc}$ & 0.459 & 0.238 \\
\hline $\mathrm{TP}$ & 0.405 & 0.168 \\
\hline $\mathrm{Pd}+\mathrm{v}$ & 0.465 & 0.244 \\
\hline $\mathrm{Pd}+\mathrm{c}$ & 0.42 & 0.219 \\
\hline $\mathrm{Pv}+\mathrm{c}$ & 0.559 & 0.298 \\
\hline $\mathrm{Pd}+\mathrm{v}+\mathrm{c}$ & 0.475 & 0.25 \\
\hline
\end{tabular}

sample $=1232$

\begin{tabular}{|l|r|r|}
\hline $200 \mathrm{~m}$ & \multicolumn{1}{|c|}{ building } & floor \\
\hline $\mathrm{Ps}$ & 0.279 & 0.043 \\
\hline $\mathrm{Pd}$ & 0.498 & 0.299 \\
\hline $\mathrm{Pv}$ & 0.71 & 0.453 \\
\hline $\mathrm{Pc}$ & 0.652 & 0.399 \\
\hline $\mathrm{TP}$ & 0.56 & 0.299 \\
\hline $\mathrm{Pd}+\mathrm{v}$ & 0.628 & 0.387 \\
\hline $\mathrm{Pd}+\mathrm{c}$ & 0.594 & 0.364 \\
\hline $\mathrm{Pv}+\mathrm{c}$ & 0.696 & 0.433 \\
\hline $\mathrm{Pd}+\mathrm{v}+\mathrm{c}$ & 0.632 & 0.389 \\
\hline
\end{tabular}

sample $=686$

\begin{tabular}{|l|r|r|}
\hline $300 \mathrm{~m}$ & \multicolumn{1}{|c|}{ building } & floor \\
\hline $\mathrm{Ps}$ & 0.484 & 0.257 \\
\hline $\mathrm{Pd}$ & 0.64 & 0.452 \\
\hline $\mathrm{Pv}$ & 0.636 & 0.46 \\
\hline $\mathrm{Pc}$ & 0.67 & 0.477 \\
\hline $\mathrm{TP}$ & 0.598 & 0.408 \\
\hline $\mathrm{Pd}+\mathrm{v}$ & 0.638 & 0.455 \\
\hline $\mathrm{Pd}+\mathrm{c}$ & 0.645 & 0.459 \\
\hline $\mathrm{Pv}+\mathrm{c}$ & 0.633 & 0.453 \\
\hline $\mathrm{Pd}+\mathrm{v}+\mathrm{c}$ & 0.631 & 0.45 \\
\hline
\end{tabular}

sample $=220$

\begin{tabular}{|l|r|r|}
\hline $500 \mathrm{~m}$ & \multicolumn{1}{|c|}{ building } & floor \\
\hline $\mathrm{Ps}$ & 0.412 & 0.222 \\
\hline $\mathrm{Pd}$ & 0.635 & 0.469 \\
\hline $\mathrm{Pv}$ & 0.661 & 0.515 \\
\hline $\mathrm{Pc}$ & 0.693 & 0.524 \\
\hline $\mathrm{TP}$ & 0.598 & 0.428 \\
\hline $\mathrm{Pd}+\mathrm{v}$ & 0.656 & 0.496 \\
\hline $\mathrm{Pd}+\mathrm{c}$ & 0.657 & 0.493 \\
\hline $\mathrm{Pv}+\mathrm{c}$ & 0.657 & 0.503 \\
\hline $\mathrm{Pd}+\mathrm{v}+\mathrm{c}$ & 0.648 & 0.489 \\
\hline
\end{tabular}

(d) Orthogonal building area with POA correction sample $=4503$

\begin{tabular}{|l|r|r|}
\hline $100 \mathrm{~m}$ & \multicolumn{1}{|c|}{ building } & floor \\
\hline $\mathrm{Ts}$ & 0.24 & 0.023 \\
\hline $\mathrm{Td}$ & 0.43 & 0.241 \\
\hline $\mathrm{Tv}$ & 0.551 & 0.305 \\
\hline $\mathrm{Tc}$ & 0.493 & 0.269 \\
\hline $\mathrm{TP}$ & 0.518 & 0.24 \\
\hline $\mathrm{Td}+\mathrm{v}$ & 0.535 & 0.303 \\
\hline $\mathrm{Td}+\mathrm{c}$ & 0.509 & 0.288 \\
\hline $\mathrm{Tv}+\mathrm{c}$ & 0.566 & 0.313 \\
\hline $\mathrm{Td}+\mathrm{v}+\mathrm{c}$ & 0.546 & 0.308 \\
\hline
\end{tabular}

sample $=1232$

\begin{tabular}{|l|r|r|}
\hline $200 \mathrm{~m}$ & \multicolumn{1}{|c|}{ building } & \multicolumn{1}{l|}{ floor } \\
\hline $\mathrm{Ts}$ & 0.403 & 0.112 \\
\hline $\mathrm{Td}$ & 0.648 & 0.42 \\
\hline $\mathrm{Tv}$ & 0.772 & 0.496 \\
\hline $\mathrm{Tc}$ & 0.721 & 0.459 \\
\hline $\mathrm{TP}^{\prime}$ & 0.72 & 0.412 \\
\hline $\mathrm{Td}+\mathrm{v}$ & 0.743 & 0.485 \\
\hline $\mathrm{Td}+\mathrm{c}$ & 0.723 & 0.471 \\
\hline $\mathrm{Tv}+\mathrm{c}$ & 0.772 & 0.494 \\
\hline $\mathrm{Td}+\mathrm{v}+\mathrm{c}$ & 0.751 & 0.487 \\
\hline
\end{tabular}

sample $=686$
\begin{tabular}{|l|r|l|}
\hline $300 \mathrm{~m}$ & \multicolumn{1}{|c|}{ building } & floor \\
\hline $\mathrm{Ts}$ & 0.584 & 0.319 \\
\hline $\mathrm{Td}$ & 0.763 & 0.563 \\
\hline $\mathrm{Tv}$ & 0.826 & 0.607 \\
\hline $\mathrm{Tc}$ & 0.779 & 0.568 \\
\hline $\mathrm{TP}$ & 0.827 & 0.576 \\
\hline $\mathrm{Td}+\mathrm{v}$ & 0.827 & 0.615 \\
\hline $\mathrm{Td}+\mathrm{c}$ & 0.805 & 0.597 \\
\hline $\mathrm{Tv}+\mathrm{c}$ & 0.852 & 0.627 \\
\hline $\mathrm{Td}+\mathrm{v}+\mathrm{c}$ & 0.839 & 0.623 \\
\hline
\end{tabular}

sample $=220$
\begin{tabular}{|l|r|r|}
\hline $500 \mathrm{~m}$ & building & floor \\
\hline $\mathrm{Ts}$ & 0.549 & 0.325 \\
\hline $\mathrm{Td}$ & 0.779 & 0.604 \\
\hline $\mathrm{Tv}$ & 0.851 & 0.672 \\
\hline $\mathrm{Tc}$ & 0.808 & 0.628 \\
\hline $\mathrm{TP}$ & 0.831 & 0.621 \\
\hline $\mathrm{Td}+\mathrm{v}$ & 0.844 & 0.665 \\
\hline $\mathrm{Td}+\mathrm{c}$ & 0.824 & 0.646 \\
\hline $\mathrm{Tv}+\mathrm{c}$ & 0.866 & 0.68 \\
\hline $\mathrm{Td}+\mathrm{v}+\mathrm{c}$ & 0.851 & 0.67 \\
\hline
\end{tabular}




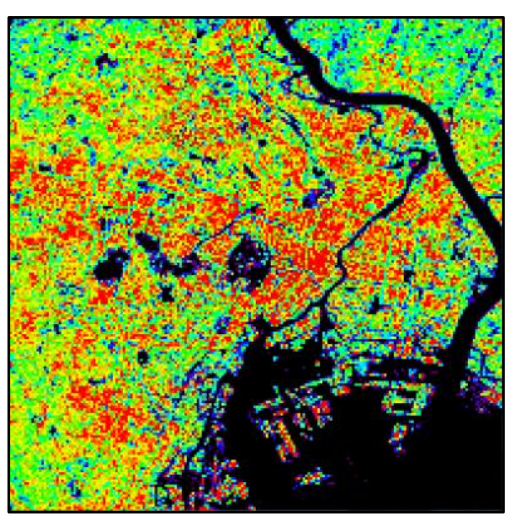

(a)

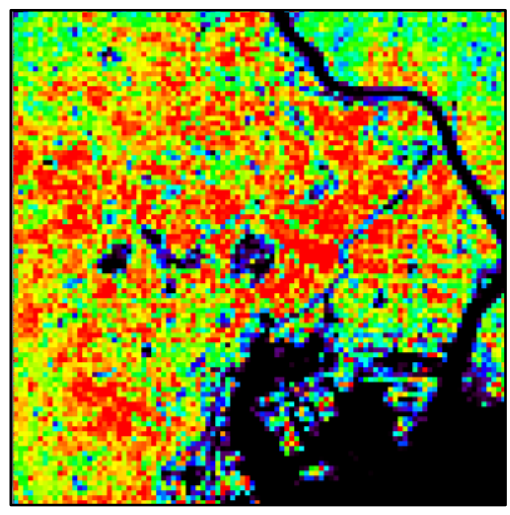

(d)

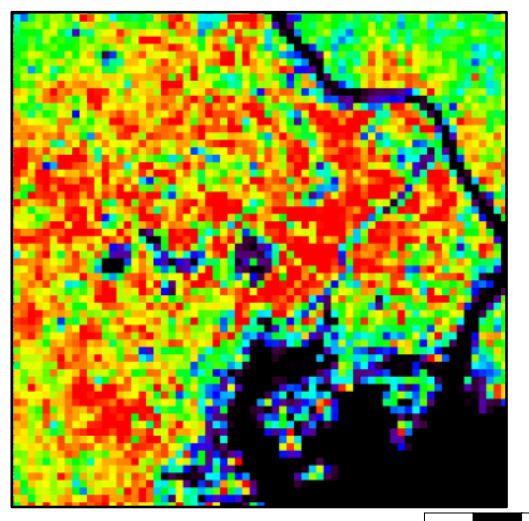

(g)

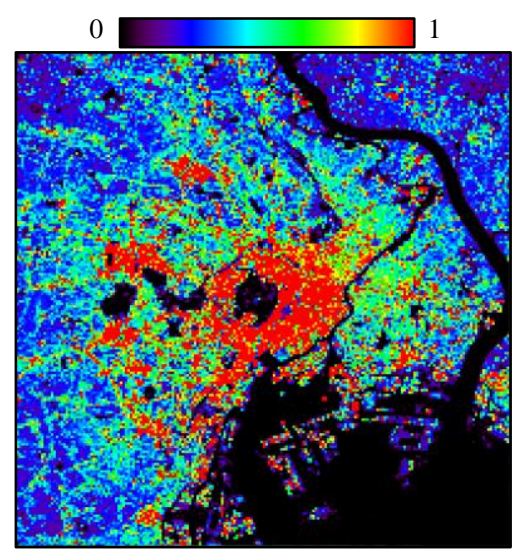

(b)

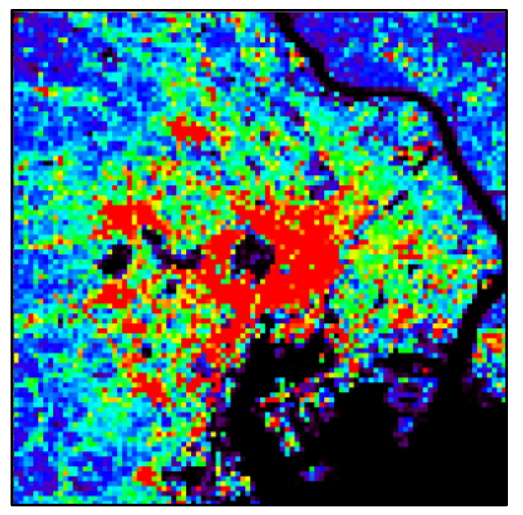

(e)

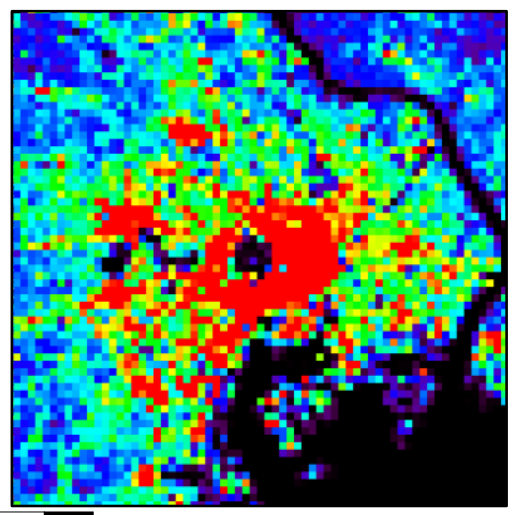

(h)

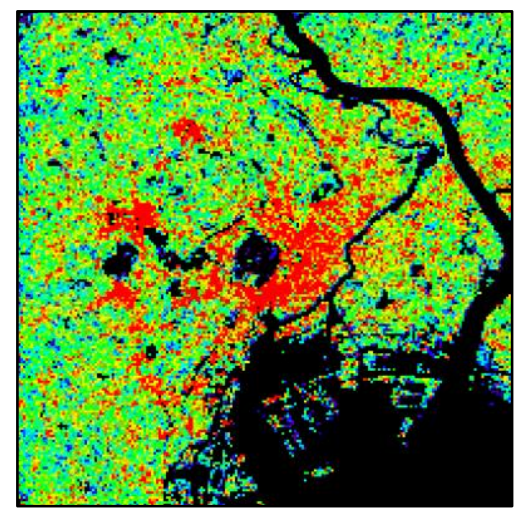

(c)

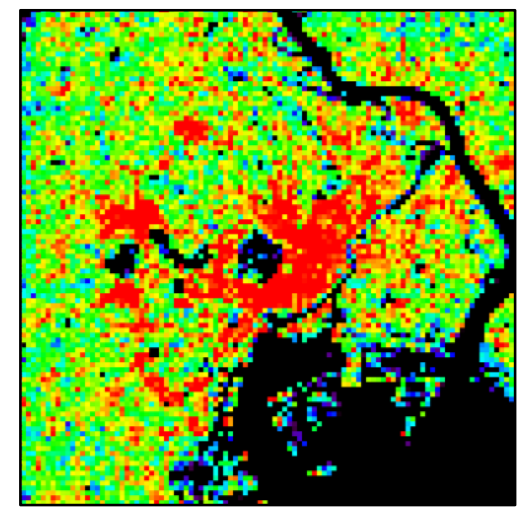

(f)

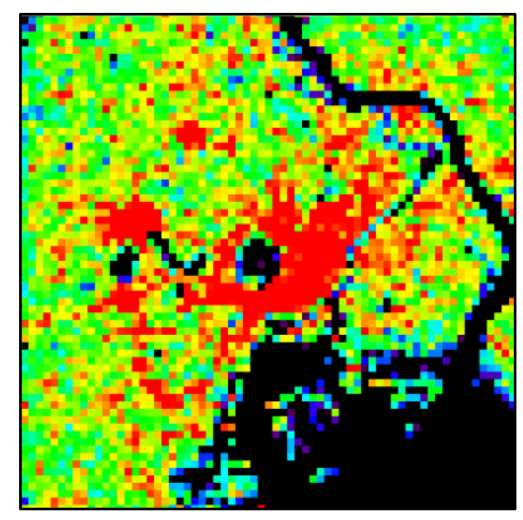

(i)

Fig. 11. Results of urban density estimation for different mesh sizes. (a), (d), and (g) building-to-land ratio; (b), (e), and (h) floor area ratio; (c), (f), and (i) Tv + c. Mesh sizes: (a), (b), and (c) $100 \mathrm{~m}$ mesh; (d), (e), and (f) $200 \mathrm{~m} \mathrm{mesh;} \mathrm{(g),} \mathrm{(h),} \mathrm{(i)} 300 \mathrm{~m}$ mesh.

\section{CONCLUSIONS}

In this paper, we have proposed an effective density estimation algorithm that can be applied to various areas. To reduce the effects of POA dependence of the scattering power, the whole POA space was divided into several intervals. However, a level of POA dependence was still seen because the surface scattering power $(P s)$ has a non-symmetrical scattering intensity histogram whose POA dependence cannot be completely removed by the proposed method. Moreover, $P s$ is very unstable against changes in the azimuth angle between the wall normal and the sensor's ground range direction in urban areas. Therefore, various combinations of the other three components were examined. $T P^{\prime}$ shows relatively good correlation with building-to-land ratio when using the whole image. However, when only orthogonal building areas are considered, the correlation is worse than the other combinations. A normalized combination of the volume scattering power and the helix scattering power $(T v+c)$ shows the best correlation with both the building-to-land ratio and the floor area ratio. POA correction method improved correlation coefficients with the building-to-land ration and the floor area ratio by approximately 0.2 on the scale of $300 \mathrm{~m}$. This improvement was seen in orthogonal building areas where a strong POA 
dependence is seen. The urban density estimated from PolSAR images seems to lie between these two ratios. SAR images are mainly related to microwave mechanisms, including the effects caused by building area and building height. It should not be expected that the urban density estimated from PolSAR images completely matches either of the two ratios estimated from GIS data. Urban density estimated from PolSAR images should be defined as a new index showing building area and building height.

Generally, building-to-land ratio and floor area ratio are calculated from GIS data. However, GIS data are expensive and sometimes unavailable, thus satellite-based estimates of urban density would be useful. The possibility of such an application has been demonstrated in this study. Even if there is only one PolSAR image, and not multi-temporal PolSAR images, of an area, urban density estimation is still possible using the proposed method. In this paper, the study area was limited to the Tokyo metropolitan area. In most Japanese urban areas, the majority of buildings are aligned in the same direction in a district. However, the proposed method is also likely to be effective in other countries whose buildings stand in a less ordered manner. This is because the proposed method utilizes the components of $P v$ and $P c$ which are robust against changes of building type. In future work we will examine the robustness of the proposed algorithm for study areas in other countries and for data from other sensors.

\section{ACKNOWLEDGMENTS}

The authors thank Prof. Y. Yamaguchi, Niigata University, and his students for providing experimental facilities and helpful support. Zmap-Town II (ZENRIN) was provided by the Center for Spatial Information Science, The University of Tokyo.

\section{REFERENCES}

[1] X. Niu and Y. Ban, "An Adaptive Contextual SEM Algorithm for Urban Land Cover Mapping Using Multitemporal High-Resolution Polarimetric SAR Data", IEEE J. of Sel. Topics in Appl. Earth Observ. Remote Sens. (JSTARS), vol. 5, no. 4, pp. 1129-1139, 2012.

[2] M. Schmidt, T. Esch, D. klein, M. Thiel and S. Dech, "Estimation of building density using TerraSAR-data", IEEE Int. Geosci. Remote Sens. Symp., IGARSS' 10, Honolulu, Hawaii, USA, pp. 1936-1939, Jul. 2010.

[3] Q. Wu, R. Chen, H. Sun and Y. Cao, "Urban building density detection using high resolution SAR imagery", Proceedings of Joint Urban Remote Sensing Event, Munich, Germany, pp. 45-48, Apr. 2011.

[4] Y. Cao, C. Su, and J. Liang, "Building unit density detection from high resolution TerraSAR-X image based on mathematical morphological operators", IEEE Int. Geosci. Remote Sens. Symp., IGARSS'12, Munich, Germany, pp. 5978-5981, Jul. 2012.

[5] M. Kajimoto and J. Susaki, "Urban area extraction from polarimetric SAR images using polarization orientation angle", IEEE Geosci. Remote Sens. Letters, vol. 10, no. 2, pp. 337-341, 2013.

[6] H. Kimura, K.P. Papathanassiou, and I. Hajnsek, "Polarization orientation effects in urban areas on SAR data", Proc. of the 2005 International Geosci. Remote Sens., pp.4863-4867, 2005.

[7] Y. Yamaguchi, T. Moriyama, M. Ishido, and H. Yamada, "Four-component scattering model for polarimetric SAR image decomposition", IEEE Trans. Geosci. Remote Sens., vol. 43, no. 8, pp. 1699-1706, 2005.

[8] Y. Yamaguchi, Y. Yajima, and H. Yamada, "A Four-Component Decomposition of POLSAR Images Based on the Coherency Matrix", IEEE Geosci. Remote Sens. Letters, vol. 3, no. 3, pp. 292-296, 2006.
[9] Y. Yamaguchi, A. Sato, W. Boerner, R. Sato, and H. Yamada, "Four-Component Scattering Power Decomposition With Rotation of Coherency Matrix", IEEE Trans. Geosci. Remote Sens., vol. 49, no 6, pp. 2251-2258, 2011.

[10] S. Iwasa and J. Susaki, "Classification of building area using azimuth angle and density indices derived from polarimetric SAR", Proceedings of Joint Urban Remote Sensing Event, pp. 269-272, 2011.

[11] J. S. Lee, J. H. Wen, T. L. Ainsworth, K. S. Chen, and A. J. Chen, "Improved sigma filter for speckle filtering of SAR imagery", IEEE Trans. Geosci. Remote Sens., vol. 47, no. 1, pp. 202-213, 2009.

[12] K. Tanaka, The Land Institute of Japan, 2011. Formulation of urban density indices by using geospatial information: A case of Tokyo Metropolitan Area. Tokyo: The Land Institute of Japan, pp. 1-49, Japanese.

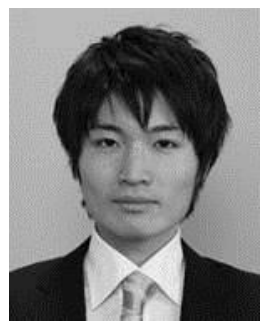

Muneyoshi Kajimoto (S'12) received the B.E., M.Eng. degrees from Kyoto University, Kyoto, Japan, in 2011 and 2013, respectively, all in civil engineering. Since 2013, he has been an employee of NTT DOCOMO, INC (NTT: Nippon Telegraph and Telephone Corporation), Tokyo, Japan.

His current research interest is in global urban mapping using building density from polarimetric synthetic aperture radar (PolSAR) data.

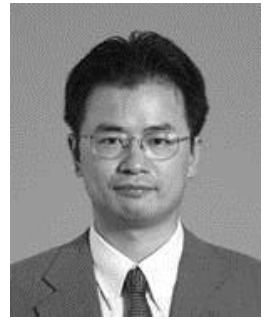

Junichi Susaki (M'00) received the B.S., M.S., and $\mathrm{Ph} . \mathrm{D}$. degrees in civil engineering from The University of Tokyo, Tokyo, Japan, in 1995, 1997 and 2000, respectively. Since 2007, he has been an Associate Professor with Kyoto University, Kyoto, Japan.

His current research interests include urban monitoring and modeling using synthetic aperture radar, optical sensors, and light detection and ranging (LiDAR) for applications such as disaster mitigation and environmental change analysis. 